\title{
SOME PROBLEMS OF LEGAL ANALYSIS
}

\author{
EMANUEL BECKER $†$
}

\section{I}

ANALYsis of law and legal questions by lawyers, courts, and most scholars has followed substantially the same pattern for many hundreds of years, wherever the common law and the rule of precedent have been accepted. Schools of legal thinking have achieved popularity and have lost their standing; philosophic speculation, political theory, and social opinion have undergone numerous upheavals; but neither these passing modes nor advances in logic, methodology, metaphysics, and semantics have had sufficient impact on the study of the law to bring about noteworthy changes in the techniques of legal analysis.

The traditional analysis of legal issues relies on principles of law, universal propositions which are legalistic in language and often ethical in connotation. These principles are to be found in the expressions of courts or legal writers who have achieved the stature of "authority." Whether they are reports of what courts have done, declarations of what they should do, or predictions of what they will do is quite generally left unstated. Thus, although few jurisdictions have passed upon the matters in question, scholars of standing affirm the status of "the law" with the authority of one or two cases alone. ${ }^{1}$ As a report of what all courts governed by common law have done, such propositions would be inaccurate. They are stated on such meager authority because the writers are confident that the principles presumably inherent or expressly stated in these cases are "sound" or represent a proper understanding of "the law." Sometimes this means that the decisions fit into a uniform scheme which conforms with their understanding of the law; at other times, although discussion proceeds for the most part on a plane of legal rights and liabilities rather than on that of ethical or political propriety, the inference appears to be that the decisions are morally correct. ${ }^{2}$ The statement of legal principle thus affirms not only what the law presumably is but also what it should and will be. In fact, when one or more decisions fail to fit the principles enunciated by a writer, they are characterized as "unsound." 3 The writer is then in effect saying this decision may state the

i Member of the New York bar.

1. See Scott, Trusts and the Statute of Wills (1930) 43 Hanv. L. Rev. 521; Kales, Contracts to Refrain from Doing Business or from Entering or Carrying on an Ozeupation (1917) 31 HaRv. L. REV. 193. Any standard textbook furnishes innumerable esamples.

2. See Ames, Two Theories of Consideralion (1899) 12 HARv. L. Rev. 515, (1899) 13 HaRv. L. Rev. 28; Kales, loc. cit. supra, note 1.

3. See Williston, Successire Promises of the Same Peformance (1895) 8 Hasv. L. Rev. 
law of a particular state, but it is not what the law ought to be, nor is it a decision likely to be adopted by other courts. Since most legal questions have not been determined in all jurisdictions, most statements of law have this triple character. But since it is the more usual practice of lawyers and scholars to refer to the law in existential rather than in normative or predictive terms, ethical questions as such do not generally come clearly to light.

The traditional method of presenting the solution to legal questions is generally through syllogistic "reasoning." " Facts are reduced to legal categories, and a proposition thus formulated is stated as the minor premise of the syllogism. The major premise is an accepted principle of law deemed appropriate to the situation. The conclusion reached is then thought to be obvious, necessary, and logical. After reaching a conclusion, it is customary to prove it "sound" by reference to precedent. When apparent unity of judicial determination is lacking, or when courts have reached conclusions seemingly in contradiction with accepted principles, resort is had to distinction. If no better basis for distinction can be found, "the gravamen of the action," "the intent of the parties to the transaction," or the "question of degree" can always be introduced. These distinctions necessitate certain assumptions that modify the principles first employed, though frequently the modification remains unexpressed. If the facts do not fit the principles or the legal categories, presumptions or fictions, often based on principles left unstated, are invoked to revise the facts in a suitable way.

Another traditionally acceptable form of legal analysis consists of classifying cases according to their facts, and adducing principles of law which subsume these facts. ${ }^{5}$ Because judges have not always stated the reasons for their decisions in a form satisfactory to scholars or other judges, and have decided cases without relying on general principles, this technique has rarely been ignored entirely by any competent analyst, and is often used in conjunction with analyses which proceed from principle. Some have carried it to the point of disregarding the failure of the courts in the very cases under considera. tion to call attention to the facts the analyst regards as relevant, or have even disregarded the expression of a contrary opinion; judicial opinions are "distinguished," "limited to the facts of the particular

27; Langdell, The Northern Securities Case and the Sherman Anti-Trust Act (1903) 16 Harv.

L. REv. 539. For criticism of such analyses see Fox, Criticism of Cases (1892) 6 HARv.

L. REv. 195. Justice Holmes was particularly incensed by such criticism. Hughes, Foreword (1941) 50 YALE L. J. 737.

4. A much less precise form of analysis is the method of analogy which is not separately outlined here.

5. John Chipman Gray defended such analysis as necessary when existing doctrines no longer explained cases. Gray, Remoteness of Charitable Gifts (1894) 7 HARv. L. REv. 406. 
case," or written off as incorrect. Judges have less opportunity to employ this method and are less inclined to do so, for it assumes that the court has failed in the past to state the law adequately, and requires lengthier opinions. However, courts do rely on a similar technique, for instance, when they admit certain types of cases must be "determined on their particular facts," or when they resort to analogy to obtain guidance from past decisions without the express benefit of principle.

These complexities of legal analysis which purport to give the law an appearance of necessity, certainty, and uniformity furnish no discomfort to the experienced student and lawyer. But to the neophyte and the careful scholar they offer a maze of confusion, for there is little doubt that if a linguist and logician without legal background were given the necessary principles, definitions, and facts, they would on many occasions reach conclusions contrary to precedents regarded as "sound law."

In recent times, the significance and usefulness of the classic pattern have been subjected to criticism in legal circles, and the customary legal analyses have been labeled as argumentative techniques, rationalizations of predetermined conclusions, and syntactic constructs. There is only partial agreement among the critics, but underlying their writings is a sincere skepticism, borne out by their experience as students of law and lawyers, as to whether traditional rationalism furnishes a reliable method of reaching correct conclusions from the premises with which analysts begin. ${ }^{6}$ Because legal analyses have purported to be founded on logic, the function of logic in actually solving issues and giving meaningful content to principles of law has been disavowed; a new banner has been found in the late MIr. Justice Holmes' statement, "The life of the law has not been logic."

Intellectual unrest among students of law has led to movements variously denominated as realism, functionalism, conceptualism, nominalism, sociological jurisprudence, and the statistical method. Some of these schools appear to deny the meaningfulness of all traditional legal analysis, or seem to believe that legal arguments and judicial opinions are little more than cloaks of conventional respectability, formal proofs of membership in the correct fraternity. Others have sought to outline a new program for studying law. Although these movements and other changes in social outlook may perhaps be credited with the disappearance of the tone of absolute certainty and august

6. To some, "correct conclusions" mean conclusions preferred by most who have preference; to others, conformance vith principles of "natural law," religious faith, or particular ethical values; to still others, it signifies formal unity with past doctrine. This article is not concerned with ethical theories or with the existence of a true "right" or "wrong." It is solely concerned with some of the methodologic problems of normative investigations and analyses in relation to the law, and will only consider ethical precepts to the extent that they are involved in such analyses. 
finality characteristic of the judicial and scholarly writings in previous decades, they have not been successful in bringing about any changes in the lawyer's thinking about the law, and have had relatively little influence on the scholar. The problem of the lawyer, judge, and student of law is, "What is the Law?" None of the newer theories claim to have devolved a new and more accurate method of predicting the law; nor have they suggested a better method of deciding a case. ${ }^{7}$ With the exception of the sociological approach, they do not offer a very weighty volume of completed scholarship as real evidence of fruitfulness. Realists have tended to delve into theory and to criticize other theorists, rather than to study the law in some new fashion or to appraise and evaluate the older method. Philosophical debates continue to grow in quantity, but understanding of legal foundations and analysis of issues has not been improved. ${ }^{8}$

The realist, nominalist, and functionalist, in enthusiastically discarding the traditional legal analysis, have become contemptuous of rationalism. Not satisfied to establish the deficiencies of traditional rationalism and its failure to accomplish its purported goal, some of them have attacked rationalism in all forms. But the new schools are unable to discuss the law without invoking in some degree "rationalist" analysis, despite the introduction of new and impressive vocabularies; for all thinking is rationalistic in nature in so far as rationalism means classification of particulars, assertion of relations between terms or classes and concepts, and between concepts and concepts, and inference of certain and probable conclusions from given premises. The foundations of the traditional analysis, therefore, require re-examination to ascertain their proper sphere.

\section{II}

Numerous assumptions are often made by the legal analyst, not always with full cognizance of their presence or tenability. Certain of these assumptions are inherent in and necessary to the traditional analysis; others are found only in particular studies. Here we will review some of the pervasive ethical assumptions so as to define the background of logical operations in law, and thereafter discuss in detail a number of problems inherent in the logic applied.

Legal systems resting on principle and "stare decisis" appear to

7. Some have stressed the importance of examining social data. But the modern schools can hardly claim credit for this idea. The late Justice Brandeis employed it before their advent.

8. The importance of theory in the study of law cannot be underestimated and the author does not intend to minimize it. The difficulty has been that different schools have contended for their own approach as the best but ignore the fact, hereinafter demonstrated, that the value of a technique is best proved in battle, not on the training grounds. In this respect, realists have sometimes been guilty of the approach they properly condemntheory unrelated to facts. 
assume that there are ultimate truths which cannot be questioned. From these principles of most general nature, numerous propositions of law are derived. The total of these principles, propositions and their implications, with statutes and constitutions are the law in its most commonly accepted meaning. ${ }^{9}$ The truth of these principles is regarded as self-evident, so that proof is never offered, and their meaning is thought to be clear without reference to their application to particular instances. ${ }^{10}$ Nor are limitations of scope indicated in their statement.

If morality be regarded as the opinions of individuals and social groups as to what ought to be and what men and society should do, many legal principles may be said to stem from past or present morality. ${ }^{11}$ Others have their origin in convention, historical accident, or apparent practicability. ${ }^{12}$ In some instances, particularly in fields of law that have not received detailed scholarly treatment, the language of the law itself reflects its moral source. We are not presently concerned with particular moral or ethical assumptions; but if law or any portion thereof is based upon morals or ethics, then there are certain general assumptions, which must be recognized for purposes of careful scrutiny. It is commonly believed that with changes in social circumstances and the birth of new issues, the law expands, but that, with rare exceptions, its basic principles remain the same. If legal principles are, however, derived even in part from morals, then it follows that the subsisting moral principles are equally static. To assume the contrary would make law subservient to a discredited past, a thesis no society would be prepared expressly to accept.

Parallel to the postulate of static morality is that of moral unity. If there is any basis for maintaining that the law of forty-eight states should be uniform, and if it is assumed that law is founded on ideals of justice as that term is commonly understood; then it must be that those ideals of justice, or morals, are universal. Or if it be conceded, as it must, that this assertion is false, then the alternative premise is that there exists an ultimate code of true morals whose perfection and certainty is not rendered questionable by the inability of all to appreciate it.

9. I have avoided throughout a definition of "law." Controversies centering about its definition are generally concerned with theories about what "law" should be. Pound, Law and the Science of Law in Recent Theories (193!) 43 Y YLE L. J. 525.

10. The nature of meaning in law will be discussed later in this article. Here the word is used in the ordinary and perhaps confused sense. I have preferred throughout to avoid the formidable language of most philosophies and to rely for the most part on contest to fix the particular meaning each word or collocation of rords intends to convey.

11. Morality in most contexts has a narrower meaning. It is used throughout in this broader sense because it appears to be a more suitable term for my purposes than "value," "preference," and other terms which predicate more definite theories of ethics and morals.

12. It was Kant who pointed out that utilitarianism was good business, not ethies. It would seem however that social and political ideals cannot eseape such considerations. 
Neither the traditional method, nor the classification of cases according to their facts, nor the method of analogy, avoid any of the moral assumptions inherent in analysis of law through a system of principles. All classificatory systems, as methods of simplification, necessitate the omission of most facts. If the classification is to be meaningful, it must rely on judgments as to the relevance of particular facts; and such judgments are based on moral or ethical principles, or at least social preferences. A classificatory system founded on categories without regard to their impact on society's or the individual's judgment of what ought to be would soon prove irrelevant and fall into desuetude as new decisions fell without the system. Analogy, too, necessitates such assumptions, for analogy consists of comparing facts and giving proper weight to identities and dissimilarities. Though principles employed in weighing similarities are often unclear, and more often unexpressed, they are nevertheless implied.

The acceptance of stated legal principles is not of itself sufficient to bring about legal uniformity or to create a legal system. Principles become part of an operative scheme when other principles may be deduced from them and when they are made applicable to the solution of particular problems. Uniformity in law necessitates a uniform system of application, an agreed system of logic operating with the rigidity of mathematical demonstration. It also necessitates universal agreement as to the meaning of the words employed in the statement of principles. Lastly, it assumes that the principles of law which are, logically speaking, the axioms and therefore primary in the legal system, are mutually consistent and contain no inherent contradictions.

\section{III}

For the purpose of analyzing some of the logical problems which appear to confuse legal analysis, and solely as a matter of convenience, we will treat with them under four headings: Legal Terms, Law and Inference, System in Law, and Law as a Science.

\section{Legal Terms.}

Terminology is fundamental to all law and legal thinking. Many legal problems center about the issue whether "X," a given state of facts, is " $A$ " or " $B$," alternate legal concepts. The tendency of courts in their opinions in some types of cases has been to treat the problem before them as if it were necessary to find the proper classifications for given facts, and nothing more. Having once determined that classification, deciding the issue merely requires the application of proper hornbook logic. It is not uncommon in this procedure to ignore, reject, or accept legal concepts without statement of reason. In some cases, the facts with which the court must contend do not fit very sedately into 
any legal concept. The practice in such a situation is to conform the facts or to treat them as if they were different from what they arewhence stem legal fictions. The court in each instance is applying legal categories in a particular context and is reaching a significant social or political result; but opinions commonly fail to indicate that any factor other than a proper respect for legal usage is involved. ${ }^{13}$

Legal language differs from all other language in its degree of unchangeability. The apparent uniformity which law seeks to retain imposes a fixed mode of speaking and writing, and, to some degree, thinking; in fact, our most brilliant judges, who have tended to disregard accepted terminology, have often been criticized by lawyers who regarded them as "too philosophical." Their opinions seem to conflict with the hornbook pattern of learning and do not furnish pat rules to be quoted in briefs with assurance. The same immutability is observable in the language of religion and morality, where the words have acquired the sanctity attached to faiths. In law, the doctrine of stare decisis, statutes, and perhaps moral conceptions and convention impose similar limitations.

The language of law is employed in what purport to be more extensive analyses than are customary in ordinary human conversation with regard to the problems of the day, but it lacks all the rigor commonly associated with scientific terminology. Many legal terms subsume numerous concepts ${ }^{14}$ which are not coextensive. For instance, the term "property" is said to refer to a certain "bundle of rights." The bundle of rights is given to considerable variation. The remedies of injunction and specific performance are sometimes included in the bundle, but not always. The bundle of rights the owner of a home may exercise is hardly identifiable with those that may be exercised by the owner of a railroad, a radio station, a newspaper, a shoe factory, a stock certificate, a bond, or personal apparel. In some instances, the rights are different because of varying governmental regulation. In some, the property right is destroyed by theft; in others, it is not. Some permit of free disposition; others do not. All such "ownership" is described as "property," a "right" protected by the constitutions of the United States and the constituent states. Such description of a legal relation as a property right, without further explication, has now become meaningless. ${ }^{15}$

A second difficulty in legal terminology which prevents scientific accuracy is the use of the same term in different contexts. A definition of partnership will help identify a type of business or organization and

13. The practise is not limited to the courts. See, e.g., Langdell, The Northerr Securities Case and the Sherman Anti-Trust Act (1903) 16 Harv. L. Rev. 539.

14. A concept is analogous to the predicate in grammar. It is an idea with which particulars may be described, and it permits the arrangement of particulars into clasias.

15. Developments in constitutional law tend to emphasize this conclusion. 
thus determine liability between the "partners" or between the "partners" and third persons, but may prove misleading if employed in tax law. Similarly, certain transfers create valid trusts for some purposes and may not be transfers at all for other purposes. The question of definition thus becomes extremely complex, for in some respects no two contexts are ever identical and each gives a different shade of meaning to the same term. It is not unlikely that one could select at random any book on jurisprudence or any hornbook and prove that its definitions are in every instance inaccurate because the terms defined are as often as not given meanings in particular contexts different from those the text writer adopted.

Traditional analysis has given little attention to this problem of language as such. It is customary when writing a book to prove the inadequacies of previous definitions and to invent a new one. The writer on property furnishes definitions without regard to the powers of the Securities and Exchange Commission, the Federal Power Commission or the reorganization powers of the court. The writer of a text book on torts does not consider the economics of monopoly and restraints of trade. Definitions in such cases are treated as a matter of formal necessity, to be formulated and ignored. The law reviews, particularly older editions, abound in arguments as to the nature of consideration, property, a cause of action, trust, tort, title, agency, etc. The authors seemed to be primarily concerned with subsuming case authority; ${ }^{16}$ often they did not ask and generally they did not answer the primary questions: To what extent will the definition distinguish possible situations so that anyone can easily determine what falls within and without the class defined? Will the definition bring about just results?-whatever the word "just" may mean to the author. The answers to these questions can sometimes be inferred. But failure to consider the questions explicitly leads to ignoring many factors that must be examined before a satisfactory answer can be had. ${ }^{17}$

16. See Williston, Consideration in Bilateral Contracts (1914) 27 Harv. L. REv. 503.

17. Because definitions have generally proved so inadequate, a technique has been developed for avoiding definition altogether. Rules for court conduct are stated; the terms are defined as operational symbols or as cues to judges and lawyers of the result to be accomplished. The Restatements of the Law offer numerous examples:

REstatement, Contracts (1932) $\S 1$ defines a contract as follows:

"A contract is a promise or a set of promises for the breach of which the law gives a remedy, or the performance of which the law in some way recognizes as a duty."

Tortious conduct is defined in 1 RestatenENT, TORTS (1934) $\S 6$ :

“. . . to denote the fact that conduct whether of act or omission is of such a character as to subject the actor [or non-actor] to liability under the principles of the law of Torts."

The definition of a trust in Resratement, Trusts (1935) $\S 2$ is:

"A trust, as the term is used in the Restatement of this subject, when not qualified by the word 'charitable', 'resulting' or 'constructive' is a fiduciary relationship 
In order to analyze further legal language it will be helpful at this point to introduce a formal terminology with which most readers are probably acquainted. Terms are said to express two distinct though inseparable ideas: "extension" and "intension." 1s Some have preferred to identify these ideas as the "denotation" and "connotation" of terms respectively, ${ }^{19}$ but for the purpose of this analysis, they will be regarded as equivalents. The connotation and intension of a term will refer to the characteristics which determine the objects or class of objects included; they delineate the particulars or classes which properly belong to the class the term denotes. Extension and denotation will refer to the objects or class of existing and possible objects specified or indicated by a term. ${ }^{20}$

Modern realists, who have been more conscious of the problems inhering in legal language, have treated the subject at length. One suggested solution for the apparent confusion in the application of legal terms is that definitions be eliminated, that terms be explained by example rather than by enumerating their connotations; it is urged that if a term is not capable of such perfect definition as to fix the scope of the particulars denoted with certainty, description solely by example is preferable. Judicial decisions on the authority of cases "on all fours" typify this approach, though of course such decisions long preceded the theory. This view is untenable for studying law or deciding cases; if words were limited to the finite class of objects which can be indicated at any given time, then there could not be a theoretic foundation or consistent method for admitting new ideas or things to a

with respect to property subjecting the person by whom the property is held to equitable duties to deal with the property for the benefit of another person, which arises as a result of a manifestation of an intention to create it."

In the introductory Note to Chapter 1 of 1 Restatevrens, Properry (1936) c. 1, the editors state:

"The word 'property' is used in this Restatement to denote legal relations between persons with respect to a thing."

These definitions it will be noted display the restaters' recognition of their inability to furnish a general concept which either denotes the class or states what the class should include. The terms have been reduced to pure formalisms. Perhaps this approach has advantages over some others.

18. Whether or not all terms have both characteristics has little bearing on the problems here discussed. My presentation, for instance, fails to account for proper names. For accurate analysis of terms and their meaning it would be necessary to distinguish "classes," "class concepts," and "concepts of class." I have attempted simplifieation and accepted its concomitant, the risk of distortion, because I do not think the point to te proved will be affected. The precise reader is referted to RusselL, Prowcrfles of MAtaEMatics (2d ed. 1938) 66 et seq.

19. Some have objected to this terminology first employed by Mill. See Josern, Azi Introduction to LoGic (2d ed. 1916) c. 5. For more detailed treatment ege Srendric, A

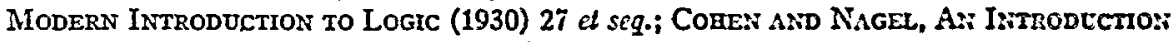
to LOGiC AND ScIENTIFic METHOd (1934) 30 et seq.

20. Some classes have no members, except perhaps themselves, such as the null class. 
particular class. Such a method is only to be found in the connotation of terms. The absence of connotations would lead to intellectual nihilism in law; legal analysis, other than an irrelevant system of case indexing, would be impossible; for the connotation of a term alone permits its extension to new or to previously unaccounted situations in an orderly way.

Some realists troubled by the vagaries of legal terminology treat it as hollow verbiage or propose to sweep it aside for a new and more meaningful language. But it serves no purpose to disregard the language of the law or to condemn it, for it is necessary to thinking about the law. Statutes adopt the linguistic tokens which appear to have meaning assigned to them in legal, social, and economic marketplaces. Interpretation of statutes without restraint would substitute judicial opinion for legislative intent. Agreements, wills, trusts, and other common legal documents rely upon the settled meaning of terms. The draftsman would founder unless he had some generally recognized vocabulary. Moreover, this accepted terminology bespeaks the conventions, morals, and climate of opinion of the past and present in common idiom, for which there is no satisfactory substitute.

To understand the question of legal definition and classification, it is first necessary to appreciate that any datum may be subsumed under an indeterminate, perhaps infinite, number of classes, each partially descriptive of the datum subsumed, yet each wholly different in connotation. Classes are employed, however, only in so far as they are relevant to the purpose to be served; and the question of purpose is determined by interest. Thus, legal classifications often include in their intension or connotation moral, social, ethical, and conventional characteristics, though they purport to be, and to some degree are, descriptive of social fact in content. Therefrom arise their dual and conflicting aspects which have created difficulties of definition and application. The question, for the sake of perfect intelligibility and linguistic accuracy, should be in all instances whether as a matter of verbal meaning a particular state of facts falls within a given class. But in the law selection of a legal classification applicable to the facts determines the issue at stake at the very same time; the question in judicial thinking thus often becomes whether, as a matter of justice, the facts should fall within the given class. The result sometimes shocks the common understanding of words and tends to make them appear meaningless. That is what lawyers imply when they say the court has given only lip service to the law. ${ }^{21}$ Yet it will be seen that the apparent distortion is not wholly unsupportable; for, since the essential

21. See Pound, Equitable Relief against Defamation and Injuries to Personally (1916) 29 HARV. L. REV. 640. 
connotations of terms are often normative, extensions in accord with normative concepts carry out the original purpose of the terms.

A brief examination of the legal concept "property" will serve to exemplify the foregoing. Every standard work on "jurisprudence" includes a definition of property, generally with the addition of new subtlety original to the author. The right to "absolute" possession or of disposition was at one time a commonly accepted definition of the term. Beginning with some such definition, lawyers and judges have been called upon to determine whether the contentions of a litigant are to be upheld because he has a "property right." Are letters property? Is news obtained by one news syndicate property, and for how long does it so remain? Are stocks, bonds, or negotiable instruments property or merely evidence of property? Are future interests property? Similar lists of questions can be formulated with respect to the terms "partnership," "income," "trust," and almost every other legal term or classification. If the answer were to be found in the definition of terms, the dictionary would then become the most useful legal source book. But it is not, and no legal analyst would make the suggestion. The reason is apparent, for the answer to these questions in many cases determines the rights of litigants-a question of justice, whatever that may signify to the particular court, and not a problem in linguistics. The question before a court is therefore never entirely linguistic, $i$. e., determinative of the relation between social fact and legal concept; in deciding a case, the court also must examine the broader policies that underlie the legal concept, since by its decision it redefines the language of the law itself. ${ }^{22}$

The value of any given system of classification from a scientific point of view is the exactitude with which members and non-members of any class may be determined. It is apparent that, so long as classes are incompletely or inaccurately defined, they serve to confuse issues by furnishing competing systems of verbiage. But the task of listing all possible particulars denoted by a class term is generally beyond the scope of human imagination and ability. Definition is therefore given by way of a general statement of ideals, and it is left for the future to furnish additional examples. In some cases our knowledge of possible fact situations is insufficient to permit a specific statement of policy, and the intension of terms employed is incapable of adequate formulation. Courts very often recognize this difficulty, which is particularly true of the earlier stages of a specific social development or legislative

22. See Warren and Brandeis, The Right of Priracy (1590) 4 Hasv. L. Rxv. 193. I am not unaware of the contentions that judges' "real" reasons for deciding cases as they do are wholly different from the factors I am now considering. I do not feel, though, that the elements here considered are wholly without import. All theories about "judicial bahavior" must recognize the influence of intellectual clarification though they assign to it but little weight. 
interpretation, by refusing to offer a detailed account of the meaning of terms and by stating they will treat with the meaning as the occasion arises, e. g., "fairness" in reorganization, "restraint of trade," etc. But in cases where definition is attempted, the duality between social or legal purpose and accuracy of factual description is apparent.

Thus it will be seen that lack of clarity in definition and exactitude in application are not solely or necessarily products of judicial ignorance or unscrupulous disputation on the part of counsel. Such difficulties are fundamental to language, for exact definition comes late in the development of ideas. Words achieve more exact meaning as they are employed; they are not born like gods with all their characteristics predestined and determined. The language of the law is an expression, however vague, of humanity's reactions as to what is just in more or less objective and universal form. Conventional definition provides a greater acceptance in the marketplace, and may, moreover, lead to a more subtle appreciation of varied ideals. If these terms are lacking in perfection so that it is not possible to recognize particulars intended to be encompassed in each instance, it is a fault only partly correctible. But to eliminate or ignore the intension of terms, however ill defined, would be to deny to the law its origins and orderly growth.

Consistency in the use of legal terminology is not accomplished by determining the set of facts to which a term has been applied nor by collating the occasional judicial definitions. Both these techniques, so common in the commercial legal literature of recent years and in lawyers' thinking about the law, are necessary but insufficient conditions for understanding legal terms. It is equally important to examine the social and economic character and ideals of the times when they have been employed so that former usage may be appreciated in proper perspective. ${ }^{23}$ The meaning thus derived from the past becomes a tentative standard for the future. As descriptive sociology and economics advance, as ideals become more crystallized and institutions more stable, it is possible to approach perfect objectivity and exact definition, for the significance of the term in application can then be more fully understood. The process also operates in reverse order. More exact terminology helps to define the ideal and thus permits more comprehensive analysis of social fact. Thus, clarity of thought cannot be introduced by some revolutionary concept. It is brought about by careful study and slow increment. As long as there is change, the task will remain incomplete.

The technique outlined has been successfully employed. The work of Thayer, Wigmore, and Morgan has laid to rest many questions of

23. Examples of this approach are numerous. Classic examples are Warren and Brandeis, The Right of Privacy (1891) 4 Harv. L. Rev. 193; Holmes, Agency (1891) 4 Harv. L. Rev. 345, (1891) 5 Harv. L. Rev. 1; Holmes, The Cosmon LaW (1881). 
evidence by explaining the function of particular concepts. ${ }^{24}$ The law of evidence has proved to be fertile ground for this approach because the legal intent is reasonably evident, and the social institution under consideration is of legal creation and therefore can be more completely known. Accuracy and precision, being more easily obtainable, have been more quickly realized. Procedural law is now going through the same process. ${ }^{25}$ Here the legislative draftsman, the academic scholar, and the bar have contributed to reducing the amount of speculation and difference of view as to the "law." Unfortunately, many courts have still to recognize that the meanings assigned to legal terms are tentative in character, and that conscious consideration must be given to the factors outlined before the past can be understood and be allowed to prescribe for the future. If stare decisis has any meaning or force, it must be grounded in a more thorough comprehension of the moral, social, ethical, and other purposive ideas expressed in the language of the law. Until such recognition is accorded, legal writings will have a limited relation to actual determinations, and the justifications of some courts for their decisions will continue to be little removed from the prayerful levels of political platforms. The modern skepticism which regards judicial decisions as "verbiage," "lip service," and "logomachy" will continue to be well founded despite the broad element of good sense imbedded beneath the free employment of hollow phrases.

\section{Lare and Inference.}

In analyzing propositions and the general theory of inference, the main concern of logicians, certainly in modern times, has been mathematics and the physical sciences. The application of their conclusions to law and analysis of law is not entirely clear, for the physical sciences and mathematics do not have the same problems of language characteristic of the law, nor do they deal with the difficult problems arising from the normative idea expressed by the word "should." Therefore, in appraising law as a rational study, it is necessary to give special consideration to its method of inference. Two common types of inference are hereinafter analyzed.

Propositions Asserting Identities. Among propositions to be found in legal analysis, those which assert a relationship between social fact and legal classifications or concepts are basic. For example: " $X$ Corporation is a monopoly," " $A$ is an agent," "The conduct of $A$ consisting of $B, C$ and $D$ is tortious." These propositions generally constitute the minor premise of the syllogism commonly employed in

24. Thayer, Presumptions and the Lawn of Evidence (1859) 3 Hunv. L. Rev. 140; Thayer, The Burden of Proof (1890) 4 Harv. L. Rev. 45; Morgan, Tlic Relation beturen Hearsay" and Preserved Mlernory (1927) 10 HaRv. L. Rev. 712.

25. See, e.g., Foster, Place of Trial in Ciril Actions (1930) 43 Hanv. L. REv. 1217. 
legal analysis. ${ }^{26}$ They assert the relationship of identity which is described by logicians as a "transitive" relationship. This means that if $A$ is equal to $B$, and $B$ is equal to $C$, then it follows, because of the transitive character of the relationship of identity, that $A$ is equal to $C$. In a science whose terms have achieved exact meanings, no problems arise as to the propiriety of inference from a series of propositions asserting the relationship of identity. Conclusions conforming to the rules of logic are as valid as when the statements have as their terms the " $A$," " $B$ " and " $C$ " of the logic books. However, the meaning of a legal term is in part defined by the conventional or legal definition and in part by the context in which it is employed. The same term in a different context may express a somewhat different idea. This raises a serious doubt as to the validity of inference from an apparently transitive relationship. It is elementary logic that inference requires a middle term, a term which appears in both premises. In law, that middle term is a legal concept or category. Thus formalized legal inference follows this pattern:

The principal is responsible for the acts of the agent.

$A$ is an agent.

Therefore: His principal is responsible for the acts of $A$.

Here the concept "agent" is the middle term. But if that term may have a different connotation or meaning because of the two different contexts in which it appears, then it follows that the conclusion drawn from the two assertions may be invalid, the reasoning false. Thus it may not be permissible to substitute for the $A$ and $B$ employed in the examples to be found in the logic books "monopoly," "agent," "mortgage," "property," "patent," etc.

This analysis does not prove that most inference in law leads to false conclusions, only that such inference does not generally conform to the rigorous standards which logic lays down for proof of a stated conclusion. Though it is not easy to assess the probability with which such reasoning will lead to false conclusions, the difficulty cannot be ignored, for it is apparent that in many instances false conclusions may be reached from true premises. For example, the law is that partnership income is taxable to the members thereof to the extent of their resfective participations in such income, and the individual tax rates are applicable. The apparent inference is that if a business organization is "a partnership" then the income thereof is taxable in the above described manner. Obviously this is not true in all cases. "Partnership" in the first context is a different idea from "partnership" in the second context. Many additional examples could be constructed to show the

26. There are, of course, many other types of propositions, some of which have been considered earlier. This article does not purport to exhaust types of propositions or their relation to each other. 
absurdities which could result from indiscriminate inference from apparent transitive relationships.

Difficulties in law do not arise when the defect is as apparent as in the example given. The analyst knows how to avoid obvious pitfalls. It is in more subtle contexts that the frailty of language can do its greatest damage. Here are two examples of how a changing context might lead to results which may or may not be acceptable though the premises were not questioned:

\section{Example I.}

Major Premise: A promise to perform an act which one is legally bound to perform is not good consideration.

Minor Premise: $A$ promises to perform an act which he is legally bound to perform.

Conclusion: $A$ 's promise to perform is not good consideration.

This logic was urged in the disputes many years ago with regard to the value as consideration of a promise of performance to a third person, when the promisor was already bound to another for the same performance. ${ }^{27}$ The major premise originated in cases relating to successive agreements between the same parties. The minor premise referred to agreements with different persons. If the major premise were limited in meaning to its origins, the conclusion would be invalid. If on the other hand it was intended to extend the meaning of the major premise, the reasoning was tautologous, and nothing was proved. Properly stated the syllogism is as follows:

Major Premise: $A$ 's promise to $B$ to perform what he is legally bound to perform for $B$ is not good consideration for $B$ 's promise.

Minor Premise: $A$ 's promised performance to $C$ is one $A$ is legally bound to perform for $B$.

Conclusion:?

\section{Example2.}

The Law: A man cannot be married to two wives, and a second marriage without a prior valid divorce is roid.

The Fact: $A$ marries $B$; without obtaining a valid divorce, he marries $C$.

Conclusion I: $A$ 's marriage to $C$ is void.

The Law: The court, pursuant to legislative delegation, may require a husband to support his wife, but the power of the court is thus limited.

The Fact: $A$ marries $C$ before he obtains a valid dirorce from $B$ to whom he had been married. 27.

27. See Williston, Successize Promises of the Sante Perfomance (1S91) 4 Hanv. L. REv. 
Conclusion II: $A$ 's marriage to $C$ is void and the court has no authority to require $A$ to support $C$.

Though the New York Court of Appeals adopted Conclusion I, a majority rejected Conclusion II. ${ }^{28}$ The entire court accepted the foregoing logic, but the majority escaped the conclusion through the rule of estoppel. Had the court recognized the distinction between "marriage" or "husband and wife" as a relationship created through proper ceremony and "marriage" as the relationship of "husband and wife" sanctioned by the laws against polygamy, it would have recognized the specious character of the logic employed.

The rationalist will regard the foregoing analysis as proving nothing more than the truism that inference requires a middle term and analysis is sometimes slovenly. He will not recognize that any question as to the validity of rationalism itself has been raised. Such a view would fail to appreciate the issue. It is more than a question of linguistics or careful presentation. Ideas are almost always conveyed through verbal or written symbols; the greater the number of symbols, the greater the number of possible relationships among them. But each relation of symbols creates a new unit in which the individual symbols, unless they refer, as they sometimes do, to a determined aggregate or are defined with a symbolism that approaches mathematics in its perfection, acquire new connotations and denotations. Logical rigor then ceases. Stated in somewhat different form, ideas about law and society are expressed by sentences from which the words employed cannot be abstracted individually as separate and complete entities expressing in all instances a single idea.

Thus, in analysis of law, the same terms are employed in many different contexts. Each context subtly shifts the meaning of terms so that it would seem at times that almost anything may be "proved" from accepted legal premises. If a term could be completely and ultimately defined so that all variances in meaning would be included, the problem would not arise. But statutes and principles of law cannot either practically or theoretically outline all possible meanings, nor can they ever hope successfully to delimit the context in which their terms may be employed. Legal analysis must therefore continue to face this very serious limitation. Its conclusions, for this among other reasons, must be regarded as probable rather than absolute; they must be checked against the source from which the premises arose rather than accepted without question.

Propositions about "Greater than" and "Less than." Another type of legal proposition introduces the element of quantity: "The gravamen of the action is fraud"; "The character and not the degree of restraint

28. Krause v. Krause, 282 N. Y. 355, 26 N. E. (2d) 290 (1940). 
determines whether certain activities are restraints of trade in violation of the Sherman Act"; "The court has greater latitude in admitting evidence in a non-jury trial." In United States v. Socony Vacumun Oil Company, the Supreme Court stated:

" 'As is true of most that takes place in a trial, the right result is a matter of degree, and depends upon the sense of measure of the judge.' See United States v. Freundlich, 95 F. (2d) 376, 379." I

It will be noted that all of these propositions share in common the ideas of "greater than" and "less than," concepts which pervade almost all thinking and evaluation. They introduce the notion of measurement. ${ }^{30}$

The idea of "greater than" or "less than" is also to be found in legal analyses which weigh the relative strength of evidence, the cogency of conflicting views, and the application of doctrines to particular cases. Sometimes the idea is not expressed in the premises of the argument but is implied in the conclusion which is preceded with the Latin phrase "a fortiori," itself a quantitative concept. ${ }^{31}$ For example: "If a principal is responsible for the criminal acts of the agent; ' $a$ fortiori' the agent is responsible." "One who acquiesces has been held a party to a conspiracy; 'a fortiori' one who aids or abets a conspiracy is a party to the conspiracy." The following are examples of court opinions, selected at random, which employ the logic of "a fortiori":

"Monopoly being clearly established any number of judicial statements can be found to the effect that instances of its baleful practices need not be shown to prove that the statute is violated. Benevolent monopoly is no less a monopoly because it is benevolent. A fortiori evidence that defendants know their business and run it in an efficient manner or even that their customers are not displeased is beside the legal point." 32

"Stated differently, evidence that the appellants had not restrained the commerce of some dealers would not prove that there was no conspiracy to restrain the commerce of dealers. Neither can such evidence disprove the affirmative evidence that they had restrained the trade of many dealers. Nor a fortiori can such evidence disprove the affirmative evidence that a conspiracy to restrain the trade of dealers had been formed." 33

29. 310 U. S. 150, 237 (1940).

30. Measurement in its simplest form is the arrangement of three or more objects or classes in order of relative magnitude. The implication of all quantitative comparisons is that there are at least three possible objects or classes which may be arranged in such order.

31. I do not agree with Professor Patterson's analysis of "a fortiori." He treats it as inference from assertions of class membership. The quoted texts which follow do not bear him out; nor would the inference expressed by the term "a fortiori" follow from such relations. See Patterson, Logic in the Law (1942) 90 U. of PA. L. REv. 875.

32. United States v. Pullman Co., 50 F. Supp. 123, 134 (E. D. Pa. 1943).

33. United States v. General Motors Corp., 121 F. (2d) 376, 405 (C. C. A. 7th, 1911). 
The tendency in the legal world in recent times to employ the quantitative idea in analysis has increased as the rigidity of mechanical jurisprudence has become more obviously unsatisfactory. It is now a common practice to solve apparently conflicting views by suggesting that it is "a matter of degree." This is an excellent method of avoiding presumably insurmountable difficulties, for if the premise that the question is one of degree is once accepted, strict contradiction is no longer possible and past precedent is no barrier to any conclusion. ${ }^{34}$ The loose thinking thus encouraged will not fail to disturb more critical thinkers who recognize that apparent "differences of degree" may or may not create differences of kind which require separate consideration, depending on the particular criteria involved.

When $A$ is taller than $B$, and $B$ taller than $C$, the inference may be drawn that $A$ is taller than $C$ where tall means relative height from a common level. Is it equally meaningful to say that because $A$ is more beautiful than $B$, and $B$ is more beautiful than $C$, that $A$ is more beautiful than $C$ ? It might at first glance appear to be so. ${ }^{35}$ But if the reader will attempt to define beauty and other concepts commonly used in society or law, he will find himself unable to arrange different instances or classes having the qualities denoted by many of these concepts in order of relative degree or amount of the particular quality present in each instance or class unless a definition wholly arbitrary and unrelated to common usage is devised. ${ }^{36} \mathrm{He}$ will find upon close examination that most concepts in their ordinary significance do not permit the quantitative determinations necessary for such arrangement. Judges of beauty contests to the contrary notwithstanding, there appears to be no standard of beauty justifying the application of a system of order, such as numbers or letters, wherein each number or letter will denote a class whose members have a greater or lesser degree of beauty. It is questionable whether Rembrandt's paintings are either more beautiful or more artistic than those of Cezanne. A trained artist or art critic would not say so; he would regard such characterization as thoughtless and lacking in.a sense of distinction. Moreover, if all qualities could be

34. Aristotle, Categoriae, c. 6, par. 5b (The Student's Oxford Aristotle, Ross edition, Vol. I, 1942).

35. I have not considered psychological reactions as a basis of measurement for it would not solve the problem of objective definition.

36. There are two kinds of measurement: intensive, which consists of arranging particular magnitudes of a given quality in order of relative magnitude; and extensive, where the numbers applicable to different magnitudes may be significantly added and multiplied. The recognized test for the latter is pragmatic, i.e., whether or not as a fact it is meaningful to add, for example, $40^{\circ}$ and $60^{\circ}$ fahrenheit; there is no theoretic or a priori method for making that determination. It would seem that despite the common use of comparison through quantity, the propriety of intensive measurement is also pragmatic, not theoretic.

I have not distinguished between magnitudes and quantities because I did not find it to be of assistance in the problems here discussed. 
analyzed quantitatively, it would follow that some things would share identical quantities of a given quality. It rould then be proper to assert that two men are equally wise, two decisions equally fair, or two legal styles equally scintillating. No critically minded person would assert any of the foregoing, for they are recognizable distortions. But if "more than" and "less than" cannot be properly applied to some qualities, it follows that inferences drawn from the assertion of such relationships are invalid.

The thesis here maintained may perhaps be better conveyed to some by stating it in mathematical terms. Inferences drawn from the relation of "more than" or "less than" assume that a particular quality to which the relationship is applied permits arrangements of things or classes of things having that quality in a linear order according to relative quantity. For example, relative hardness is arranged in an order from 0 to 10. But there is no reason to believe that all qualities permit of linear arrangement. Absent proof of the propriety of such arrangement, transitive inferences are wholly gratuitous. Thus it is improper to select at random a particular quality, to assert that $A$ has more of that quality than $B$, and to employ without further investigation the type of inference sometimes preceded by the expression "a fortiori."

Since some qualities are measurable, i.e., allow for arrangement in a linear order according to relative quantity, inquiry must be directed to the method of distinguishing them. In purely abstract relationships of which mathematical systems are the perfect example, formal inference is of course appropriate. In no other instance can the question of the propriety of inference be answered theoretically; it can only be determined pragmatically. The first question is not whether as a matter of logic the deduction is permissible, but whether as a matter of fact a group of different classes or things haring a common quality can be arranged in a linear order based on some idea of relative quantity. If they can be so arranged, the inference from assertion of a quantitative relationship is permissible; otherwise it is not. Some qualities may not be measurable because of lack of sufficient definition. The solution in these cases is perhaps to be found in the clarification of language and the introduction of more precise concepts. But it is problematical whether most human, ethical, and legal standards permit such definition. It is also to be doubted whether such definition will leave to a term sufficient meaning for expressing the ideas originally intended to be conveyed. Nevertheless, qualities that do not permit quantitative analysis occupy an important place in society, and law. Probably all moral precepts are to be found among them. The absence of a quantitative character because of insufficient definition or othernise does not mean that the qualities of fairness, equitability, social importance, democracy, and many others are without significance. One might as well deny the 
existence of attractive and unattractive smells because "there is no known method of defining perfumes. Until recently, differences in colors could only be vaguely defined, and their arrangement in an intelligible order was not precise. ${ }^{37}$

Theories contradicting commonly accepted ideas rarely receive acceptance and often prove to be unfounded. The foregoing might be subjected to the same criticism unless the theoretic foundations of much intelligent work which has employed the type of inference sometimes introduced by the expression "a fortiori" can be explained. Such an explanation does exist. When precise mathematical reasoning is not applicable, it may nevertheless be introduced and employed by analogy. Analogy is an imaginative and partly imperfect method of relating facts otherwise distinct by inexact comparison and contrast. The difference, for present purposes, between analogy and inference is that analogy does not assure conclusions, and it is improper to rely on it as the mathematician relies on logical validity. The importance of analogical thinking cannot be overappraised; the Socratic dialogues are sufficient proof of the advances that may be made in human understanding by employing it. At the same time, these dialogues demonstrate the numerous pitfalls into which even the wisest can fall when they carry analogy too far or rely on it as proof satisfying the canons of logic.

The foregoing analysis does not prove that all inference is purposeless. It does not establish that the work of able scholars is lacking in merit. Valid inference is the method of reaching with certainty true conclusions from premises postulated as true in the particular universe under consideration. ${ }^{38}$ When the inference is invalid the conclusion may or may not be true. The frequency with which an invalid or probable inference will lead to a true conclusion varies in each particular case. But in law it is doubtful whether anyone would be prepared to accept a "probably" valid result. The test for truth must therefore be found elsewhere.

System in Law.

If logic is an organon for determining the adequacy of formal proof in support of a proposition, or consists of principles for the unification of a particular field of learning, it is necessary to inquire what justifica-

37. Russell has suggested linear arrangements in terms of relative similarity; it would not however solve the problem raised here.

38. The classic problem as to the nature of truth is not here involved. Within a given universe truth is established by the postulates of that universe. Thereafter all the implications of these postulates are "true." It may be that this definition of truth "begs the question." There are others who maintain that if the universe is sufficiently large to encompass the existing world, that is not a serious objection, for all learning in the larger sense "begs the question" by the very fact that it is scientific. This metaphysical question is not discussed in this article for its ramifications extend far beyond the present thesis. 
tion exists for the application of logic to analysis of law and legal problems, and to ascertain whether the law permits systematic presentation more significant than arbitrary division into subject headings. It might be maintained, perhaps successfully, that deduction from legislative enactment is authorized by the intention of the legislature. To the extent that statutes do not conflict and their terminology accurately denotes classes intended to be encompassed, statutory law permits logical deduction. Although it is recognized that statutes conflicting with the accepted past will generally suffer distortion in court, draftsmanship is the major problem underlying clarity. But the common law lacks the authority of statutes, so that the justification for applying logic to principles of law must be found elsewhere.

System is the ideal of all fields of learning; for it is the accurate arrangement of data in symmetries, significant in terms of human interest and further discovery. It creates the outline for a unique pattern, and, by making apparent the unfilled portions of this pattern, furthers investigation and discovery. In the sciences, principles for valid inference are the framework of system of which the ultimate purpose is sometimes prediction and at other times the organization of a multitude of diverse factors in an intelligible and usable way. When a body of knowledge acquires systematic order with a high degree of rigor by observing the rules of inference, it becomes a powerful instrument for advancing knowledge. Thus mathematics received its greatest impetus from the introduction of more rigorous proof. The tests of the usefulness of a system in law as well as the physical sciences are accuracy of prediction and internal consistency. It has been demonstrated that legal logic has a number of defects, which suggests that a rigorous system in most fields of law cannot be easily achieved. But even if it were assumed that a degree of formalism could be successfully evolved so that inference was unquestionably valid, internal consistency and prediction would not be an immediately accomplished fact.

Since law has among its sources epigrammatic statements purporting to be true principles of justice, and since legal propositions often reflect that source, it is to be expected that many will prove to be contradictory in particular application. Even in relatively technical fields of law, direct contradiction is not uncommon. The customary court solution of conflicting principles is to ignore one principle in favor of another, and thus to retain both principles, one of them partly weakened but intact so that it may be urged by lawyers at later times and employed without reserve except in a particular context by judge and scholar. Obviously, though, the ideal of system has been perceptibly weakened. It is, moreover, unreasonable to expect that some method could be devised to eliminate such contradictions. Society always has conflicting ideals which do not permit solution by logic 
alone. It is difficult to reject many of these ideals because of their long standing and common acceptance. They represent our historical views as to what is just.

History and social diversity are not alone in contributing to the law conflicting principles and conflicts from principles. If the law were left to scholars to write out anew, consistency could not be maintained no matter how learned the courts became, and the apparent direction of logic would be ignored on many occasions with general approval. Moreover, there is reason to believe that a theoretic system of law could not be founded on ethical principles acceptable in modern American society. Justice as a social ideal for the solution of legal controversies and social conflicts, whether it be founded on principles of democracy, natural law, or the layman's sense of fairness, honesty, and decency, cannot be a perfect unifying principle of legal or social behavior for reasons that will become apparent upon closer examination of the character of the legal "ought."

Normative systems have been a subject of interest to ethicists since ancient times; consequently their work is a convenient base for examining the propriety of legal consistency as a primary standard for the law. Some ethical systems derive their authority from a transcendental source or holy work. On occasion "right reason" has been regarded as the "first principle" of authoritarian systems. Kant sought to lay the foundation for his ethics in a "transcendental logic," principles of unity among abstract ideas untarnished by concepts applicable to the perceptible ("phenomenal") universe. These systems justify deducing particular rules from given principles if they assume, as they generally do, that "reason" is given by some authority as a fundamental precept, and that the irreducible vagaries of human nature are irrelevant in determining right and wrong. As a matter of fact, though, such ethical systems generally lead to some contradiction and are subject to all the weaknesses of language and inference raised earlier with regard to legal analysis. Moreover, human reactions and ideas about happiness do find their way into these systems in roundabout fashion to detract from their elegance. ${ }^{39}$

Many non-religious ethical systems purport to derive their authority from some standard of social or personal good. Ethicists select one or more ideals which men or societies, they believe, desire above all other things in their more "rational" or thoughtful moments, and make these ideals the standards by which all social or individual conduct is to be judged. After defining these ideals, sometimes to the point where they are little more than operational symbols, ${ }^{40}$ and after establishing their

39. See Sidgwick, The Merhod of Etuics (4th ed. 1890) 80.

40. Operational symbols are words reduced to mathematical symbols having no external references and which are defined solely in relation to other symbols of equally limited character. 
unique superiority over all other ideals, they purport to deduce a system the propositions of which distinguish between right and wrong, good and bad. But the ultimate justification for these systems is always the same, some quality in man, whether it be the "rational faculty," "feeling," "intuition," or precepts analogous to explanations for the existence of universal standards in classic art. ${ }^{41}$

For the purpose of this analysis we may ignore the objection sometimes made to many of these ethical systems, that they are lacling in moral quality, and ask what justification such ethics have for employing logical deduction in deriring particular rules of conduct. If they purport to report all human reactions or particular types of reaction, then the validity of the system would depend on the accuracy of observation. But ethicists do not make investigations or collect data satisfying the standards of any science. Nor would ethics relying on scientific investigation alone have much appeal. Right and wrong would be lost in psychology and psychiatry, and moral suasion would give way to the experimental laboratory. This would not be acceptable to ethicists. The laboratory, if it ever fulfils its ambitious prosram, will explain the physical and social origins of human conduct; but it would not to the mind of ethicists furnish rules for determining good and bad, right and wrong, for the latter are normative, not existential, standards, i.e., they describe what peoples and societies should be lilie, not what they are. ${ }^{42}$ If, on the other hand, the ethicists are reporting particular expressions of what is right and wrong which, because they are most enduring or for some other reason, are to be selected as the premises for an ethical structure, their systems still lack a postulate for the introduction of the rules of logic which will permit the specification, through deduction, of particular rules of proper conduct. ${ }^{43}$

The explanation for ethical methodology must be that the ethicist

41. Sidgwick appreciated the methods of ethics better than most. He wrote: "The aim of Ethics is to render scientific-i. e. true, and as far as possible systematic-the apparent cognitions that most men have of the rightness or reasconablenes of conduct, vihether the conduct be considered right in itself or as the means to some end conceived as ultimately reasonable." Smgwick, The Mifthod of ErHics (4th ed. 1890) 77.

42. This distinction, some will suggest, is utterly without merit. But although psychology may be able to explain the origin of some of these attitudes, it is not yet prepared to take the place of ethical speculation; men still live by and die for ideas of right and vrong and their conception of personal freedom; they still know and believe in "moral" indignation, fairness, honesty, and preserving faith. These and many other ideals are the foundation for administering justice. There are not many who bolieve today that fascist and nazi gangsters should be left to the psychiatrist. MIuch more common is the view that they should "pay for their crimes, because -?" The reasons are ethical propositions or moral views unproved and unprovable in the scientific sense.

43. Santayana's restatement of Greel ethics in The Life of Rrasos offers a different approach. He recounts the good life as it would unfold in the expression of emotion through the discipline of "reason." He was, however, aware that man was not given to such a life and that he was only outlining what he regarded at the time he wrote as an attractive mode 
regards man as a rational being who, if he is conscious of his true nature, can give to his "moral" impulses or their expression a rational unity. This assumption seems wholly gratuitous. Even if human conduct were explicable in terms of "conditioning" or reflexes, it does not conform with ethical standards. Human reactions do not have their source in any rational faculty which orders them in accordance with given ideals. In terms of such ideals these reactions are likely to be more often irrational than rational, more often contradictory of standards professed than consistent with them. Some might suggest that man should be rational even though he generally is not. But one could urge with equal cogency that man should be beautiful, selfless, courageous, or saintly. The idea is perhaps exhilarating but begs the question. Nor is there any inherent necessity for believing that expressions of moral sentiment carry with them all the implications the ethicists infer. It is natural for philosophers, who are generally logicians by predisposition and training, to regard reason as an overriding quality of human nature which all are prepared to consider in passing upon the propriety of conduct. But it is apparent, as the law itself proves, that men are willing to maintain some premises but not their implications; they will accept one view and refuse to deny an apparently contradictory assertion. ${ }^{44}$

The methodology of early legal writers was similar with that of the ethicists. Some of them believed they knew the ultimate truths, and, in the grand manner characteristic of eras where doubts were not too openly expressed or too often respected, they outlined the law and its logic. The more recent tendency has been to find some justification for the law by referring to social welfare, morals, or mores. But if the common law does not descend from a superior being which incorporates the logical implications of its dictates, what justification is there for applying complex schemes of logical manipulation to particular standards derived solely from men's passing expressions of what they deem to be "just," "right," and "fair." If society's views of right and wrong were inherently consistent, or if all the hopes, desires, and judgments of its members emanated from a determined pattern, then it would be proper to begin with some principle and inexorably carry out its conclusions.

of existence. He also employed "reason" in a different sense from the ethicists' logic. Sec Santayana, The Life of Reason (2d ed. 1932) Preface.

44. This thesis will be attacked as irrational, and probably as confused, because it will be claimed that, if one is not prepared to accept the conclusions from premises, he is not prepared to accept the premises themselves. That is so if the premises are true universals and were intended as such. This does not appear to be the case. Men's ethical expressions are perhaps overzealous and stated in the form of universal propositions, but to treat them as such is to give them a solemnity subsequent expressions generally contradict. This does not mean that there can be no organization of expression; but it must proceed from observation, either psychological or sociological, not from pretentious outlines which presume to have the authority of mathematical demonstration. 
But there is no evidence for such belief; men and societies might find certain premises agreeable and valid conclusions drawn therefrom disagreeable. Nor is there any evidence for the contention that some judgments and their implications are inherently the correct ones. ${ }^{45}$ It does not suffice to argue that the premises need to be redefined, the legal principle to be restated. Moral and legal judgments in less analytical form may reflect the morals of a people more accurately than logical subtleties introduced to eliminate contradiction. No reason exists therefore to assume that a people's judgment of justice has any logical unity or that there is any injustice in the lack of such unity. That logic has moral suasion is undoubtedly true, but so has rhetoric and poetry, neither of which rely on logic. The logician does not necessarily have the best moral insight and may not be the wisest judge.

Social welfare or other political ideals might at first seem to offer a source of authority from which a system could be adduced. To the extent that a society is uniform and its ends reasonably defined, a limited system can be derived by examining social data. Though this approach is thought to be a modern one, it enjoyed successful application in earlier days when society was simply constructed, its ideals more generally accepted, and the impact of law upon society easily determined. For that reason early writers who developed the law through logic and a few elementary principles perhaps came closer to the truth than those who write today along the same lines or employ statistics. Ultimately, however, "social welfare" and other political ideals have inherent in them the elements of a more or less confused moral scheme and retain their authority so long as social morality and mores remain uniform. Furthermore, these standards can only furnish a limited group of rules for judicial conduct. The larger part of judicial administration cannot be determined by the benefits to society as a whole except to the extent that "the true administration of justice"whatever the expression signifies-is beneficial to society.

If man's sense of justice submits to no known order, and if the expressions of his views cannot withstand the test of logic, then it follows that his acceptance of a premise will not guarantee his acceptance of a "valid" conclusion from that premise. We may assume that in most instances he will accept the conclusion and agree that reason itself is very persuasive. But if reason is not an ever-controlling motive or consideration, then logic will not furnish a universally acceptable result in all cases. The final test of a normative conclusion inferred from principle is therefore not to be found in the principle and logic but in the

45. It may be that there is an ultimative morality having a logical unity just as come musical forms have a symmetrical character. I do not intend to rule this out. I maintain, however, that such a morality has not been discovered and its accuracy demonstrated. It seems unlikely to me that this will be accomplished. Moral expressions are always social in form and the abstraction of its pure essence, if such there be, seems a dubious possibility: 
sources from which the principle stems, conventions, religion, morals, public opinion, and others. Thus, by a wholly different mode of analysis and for different reasons, the foregoing suggests the same modus operandi to the judge and scholar that is indicated by logical pragmatism, ${ }^{46}$ at least to the extent that they both require examination of conclusions independently of premises.

Unless justice is founded on supernatural principles, systems of broadest generality in law cannot fully achieve the ideals of predictability, or accurate description. The ultimate datum, for the purpose of predictability, is a sense of justice; for accurate description, court determination. Summation of the past with a given set of propositions no matter how accurate will not determine the future. The same propositions which describe all decided cases may be utterly irrelevant to the intention and meaning of the law and will not furnish a reliable index to what courts will do. The introduction of a predictive level shifts the reference of legal propositions to their origin in society and to the aims of justice. What courts should and are therefore likely to do, as well as what they have done, becomes the ultimate data to be considered in a predictive legal system. Normative principles, when founded upon psychological ethics or the beliefs of a given society, are not likely to furnish a trustworthy source for accurate prediction in any system actual or proposed because, as has been demonstrated, they lack inherent consistency. On the other hand, no particular transcendental or religious ethics have sufficient general acceptance in this country at the present time. A system limited to describing past determinations may have the merits of index, as a method of denoting varying particulars. Contradictions must, however, be guarded against, and accuracy of description is retained only by avoiding broad generalization. Such studies remain classificatory and descriptive and never assume the outlines associated with legal systems.

\section{Law as a Science.}

The rationalist standard of scientific unity has not been achieved in law, and for the reasons noted, among others, it is not likely to be realized. Simple logical manipulations contain numerous hazards of a purely logical nature, and the justification for honoring the logical implication of legal propositions is questionable when the ultimate standard of law, its criterion of truth, is a sense of justice only partly defined or expressed. A science of law through systematic presentation from first principles without regard to public acceptance of each particular proposition would soon become totally devoid of any relation to reality. But a few logical permutations are necessary before legal propositions

46. By "logical pragmatism" I refer to the philosophic doctrines of Charles S. Peircenot to the numerous other types of pragmatism which appeared later. See 4 PEIRCE, CoLlected Papers (1933); Peirce, Chance, Love and Logic (1923). 
become disassociated from their original point of reference. Therefore, the propositions of such a legal science would no longer be either true or false. They would approach the character of what Russell calls propositional functions-formal outlines furnishing interesting intellectual constructions which may or may not be imposed on facts. ${ }^{47}$ The terms of such legal propositions would be capable of sulsuming almost all particulars and would therefore be without significance with regard to any.

Although law has been called a science, it must be conceded that it has not been unified into one or more complete systems. ITe have analyzed system in law because every analysis at all complex, and the law books abound in them, represents an attempt at systematizing. Abstraction occurs in greater or lesser degree in such analysis, and its lack of reality, when generality is more marked, is demonstrated in application. Agreement on general principles does not assure agreement in particular application, and proofs of contradictory conclusions are equally persuasive, equally valid. Disputes not uncommon even in recent times as to what is a "cause of action" or as to the true nature of "consideration" or "choses in action" all involve a degree of abstraction and assume the propriety of applying systems of inferences far beyond that which the subject matter permits. Even the Rule aggainst Perpetuities, presumably a mathematical concept, cannot be subjected to long-drawn analysis. Gray's brilliant work furnishes a very fine and apparently logically sound series of inferences from the Rule, yet his system is not altogether acceptable to the courts. It is a fact that courts generally avoid extending principles very much beyond the facts which first occasioned their enunciation.

Aristotle notes in his Ethics that a subject can never be treated with a degree of refinement unsuited to itself. It would appear that the failure to recognize this elementary wisdom is the reason why much learned legal literature has not significantly advanced understanding. Brilliance in variety of deduction and subtle distinction in analysis may earn popular approval, but it is often more misleading than enlightening. Probably these considerations have caused experienced trial lawyers to concentrate on rhetoric rather than logic, and on the detailed facts of the particular case rather than on the logical application of legal lore. They realize that appeals to sympathies are appeals to one of the true sources of law.:3

The limitations of law as a science do not justify the contention that the only proper approach to the law is through the single case analysis or the hunch judgment of the "practical judge," nor do they offer solace to the nominalist who regards all human understanding as memoriza-

47. Russell, Principles of Miathematics (2d ed. 1938) 82 ct scq.

48. Cardozo, The Growth of the LaW (1924) 57. 
tion of verbal patterns. All communicable knowledge must assume the form of classification, the relation of particulars to classes, inference, and systematic arrangement. The fact that the legal universe is not completely intelligible and rests in part on irreducible and irrational factors does not justify the abandonment of study, analysis, inference, and generalization to the extent that they encourage and aid understanding. Nor does it suggest that our culture and traditions may be forgotten without loss of insight and character. The truism, that all things unfit for the gods are not to be thrown to the dogs, appears to be lost on those who assert the contrary.

The implacability of law does not lead to the conclusion that the early and modern systematic legal studies are void of any merit or that rationalism cannot be helpful in studying law. It is true that such studies as systematic presentations have failed. But they furnish guides which bring to the solution of the particular problem a wealth of critical thinking about the considerations which must be weighed, albeit haphazardly, in arriving at intelligent and intelligible decisions. They have probed the potentialities and limitations of different ideas that have been regarded as persuasive on different occasions, and have outlined some of the consequences, and therefore the partial meanings, of these ideas. As critical analyses many of these studies have been helpful in rooting out false notions which had gained acceptance by hiding intellectual confusion with learned language. Their failure has not been a total failure to furnish enlightenment but rather an inability to appreciate their own limitations.

\section{IV}

It would appear that the origin of the difficulties of the traditional analysis lies in three assumptions accepted in part or in whole at different times:

1. There is one system of law, and that can be ascertained.

2. The law is predictable because there is a reasonably perfect unity between the past and the future.

3. No distinction need generally be drawn in discussing law between the existential and the normative.

The result of these assumptions is that no careful lawyer or student of law relies to any great extent on many legal writings. Works to which scholars of brilliance have devoted many years are very often employed only as indices to relevant cases, and perhaps as secondary authority in briefs when other authority is not available. Books which should have been an inspiration to understanding have served too often as glorified digests.

If scholars were more aware of the defects in these assumptions and asked themselves, "What am I writing for?," they would not have fol- 
lowed the pattern of earlier writers such as Kent, Bishop, Story, and Bacon. The technique of the latter, however helpful in understanding the law of that day by casting into better perspective the tradition of the common law, is no longer sufficient. The scholar must determine whether he wishes to investigate and report one or more of the following: history of first principles; court decisions and their meaning; the relation of law and society; what the law will be; what the law should be. All of these subjects are closely allied, and a complete study of any one necessitates some understanding of the others. The importance of recognizing the distinction among them is to make analysis more pertinent to its particular ends and eliminate the ambiguities and inaccuracies which otherwise arise.

Historical studies reflecting appreciation of the relation between law and its function in society are numerous. Mr. Justice Holmes, among others, examined legal doctrine in terms of the social data to which it was applied and the intellectual climate in which it grew. His approach considered the "felt necessities of the time" and the passing social prejudices. Realism to Holmes meant that he could bring to bear a vaster appreciation of the past and derive from it a richer learning. Holmes recognized that the study of history could furnish enlightenment to free the present from the linguistic manacles of the past and to refashion the legal tools for service to the future. ${ }^{49}$

The meaning of court decisions as a subject of investigation offers a great number of possibilities. Their significance in terms of future court attitude, their impact on society, ${ }^{\circ 0}$ on the presentation of a cause before a court, and on the drafting of documents ${ }^{~} 1$ have been the subject of valuable articles. The degree of permissible generalization and specification in reporting the meaning of decisions is, however, governed by the criteria of accuracy and usefulness. 52

Prediction of future judicial decisions in many fields of law requires consideration of factors too numerous and too uncertain or indefinite

49. See particularly Holnes, The Common Law (1S81); Holmes, A gency (1891) 4 Harv. L. Rev. 345, (1S91) 5 Harv. L. Rev. 1; Holmes, Pritilege, Afalice and Intcrs (1894) 8 Harv. L. Rev. 1; Holmes, Exceutors (1895) 9 H.ARv. L. Rev. 42. See also Warren and Brandeis, The Right of Prizacy (1890) 4 H.1Rv. L. REv. 193; Pound, Equitalle Religf accinst Defamation and Injusries to Personalty (1916) 29 H.arv. L. Rev. 640.

50. The larger part of their work has been devoted to "political" issues and secial legislation. See note 49 supra; Frankfurter, Hours of Labor and Reolism in Constitutional Law (1916) 29 HARv. L. REv. 353. Courts quite generally consider the impact of a decision upon litigants and society although they do not always express their views and are often unable to fit them into the type of analysis they regard as judicial.

51. See, e.g., Leach, Perpetuities in a Nutsicll (1938) 51 Harv. L. Rev. 638; Ames, Two Theories of Consideration (1S9S) 12 H.1Rv. L. Rev. 515, (1S99) 13 H.Anv. L. REv. 29.

52. See Sturges, Arbitration (1930); Williston, Releases and Cocmants Nos to Sise Joint or Joint and Sereral Debtors (1912) 25 H.1Rv. L. Rev. 203; Scott, The Trustee's Duty of Loyalty (1936) 49 Harv. L. Rev. 521; Leach, State Law of Eridence in the Federal Cotst's (1930) 43 HaRv. L. Rev. 554. 
for the lawyer or scholar to feel that he can predict with a fair degree of probability. ${ }^{53}$ For that reason more attention has always been given by the practical lawyer to finding the solutions to his problems in terms of relatively "well-settled law." Recently scholars have considered this approach.

Law as a normative study has been examined mainly from the point of view of unity with tradition, though there are notable exceptions. Normative studies also require comprehension of ethics and society. Writers who advocate a particular view on social or ethical grounds seldom furnish evidence to support their opinions. They tend to employ words like "liberal," "unsound," "fair," and fail conclusively to demonstrate how contrary views are not equally "liberal," "sound," or "fair"; nor do they define these terms sufficiently to make them more than stamps of personal approval or disapproval. Thorough examination of the normative aspects of any legal problem is, of course, a herculean task whenever the issue is closely examined. But this does not justify facile conclusion, nor does it save the necessity for examination.

\section{ConCLUSION}

Arguments about realism, rationalism, and other theories of law do not solve the question of how to study law in any of its phases. Whether or not future judicial decisions can be predicted, and whether or not the past will permit significant generalization, is not to be found in theories. In each study and in each field of law the answer to the apparent difference of view between rationalist and realist rests in both experiment and sound scholarship. If it is found possible, as it has been in some instances, to state fundamental concepts with clarity and derive particular decisions from them, much has been accomplished. If the social institution in which the legal concepts are employed is well defined and the underlying ethical and political philosophy is agreed upon, or if a field of law relates to court procedure or to documents customarily drawn by lawyers, then neither theoretic nor practical objections to limited systematization are insuperable. Legal generalization should not therefore be condemned or mocked indiscriminately. The task is to fix its limitations and to encourage its development with greater rigor than in the past.

The classic approach to law, conscious of its own limitations and appreciative of its purposes and the significance of its symbolism, does

53. Older writers thought they had predicted legal decisions when they had stated what the law was. See Ames, Two Theories of Consideration (1899) 12 HArv. L. REv. 515, (1899) 13 HARv. L. Rev. 29. Some writers still make the same assumption. Others, particularly those who write on tax law, or other subjects to which the United States Supreme Court has recently devoted itself, tend to recognize that they can only state trends of the Court which might turn in any one of a number of directions. 
not exclude from the law any of the newer or more theoretic learning; it is sufficiently broad to admit, if not require, the results of scientific investigation and of doctrinal clarification. Advances in science and changes in culture may serve to redefine legal principle and terminology without violence to whatever unities underlie the common law. This process has always taken place, though generally, beneath the camouflage of apparently "hollow verbalism," the subject of so much criticism. ${ }^{54}$ If the social sciences, ethics, and psychology have not been more consciously integrated into the fabric of the law", and if "positive" law still rules the judicial roost, the fault lies in part with the advocates of the more modern approaches. The difficulty has been that the proponents of new philosophies of law have not furnished to the judge, lawyer, and legal scholar a methodology which would permit the systematic application of their theories and studies to the daily grist of judicial decisions and legal analysis, although the methodology was always available to them, for it is inherent in the traditional legal analysis.

54. There are noteworthy exceptions: Holmes, Brandeis, Cardozo, and a number of contemporary judges. 